\title{
The Effect of Customer-Company Relationship on Internet Adoption in Jordanian Small and Medium Enterprises
}

\author{
Ghaith Mustafa Al-Abdallah \\ Applied Science University, Jordan \\ ghaith.abdallah@yahoo.com
}

\begin{abstract}
Internet is a new effective way to conduct business and marketing. It is used widely in the developed countries because of its unquestionable benefits especially for small and medium enterprises (SMEs) where internet provides great potential for such firms to compete world wild. SMEs are very important component of the national economies and are estimated to account for 80 percent of global economic growth. In developing countries, such as Jordan, internet adoption for marketing activities can be very helpful to SMEs. The main objective of this research is to examine the customer-company relationship effect on internet adoption in Jordanian SMEs, and highlight the actual use of internet in SMEs that adopted internet for marketing activities. One main and three sub- hypotheses were formed based on the literature review and previous studies. A restricted research methodology was used and the hypothesis was tested over a proportional systematic random sample obtained from the official records of Amman Chamber of Commerce. Data was collected through questionnaires, 270 personally submitted questionnaires were distributed to the decisions makers in Jordanian SMEs. Statistical Package for the Social Science (SPSS) was chosen to describe and analyze the data of 253 filtered and screened questionnaires. Results and discussion, conclusion, and recommendations were provided.
\end{abstract}

Keywords: Internet Adoption, Customer Company Relationship, Customer Loyalty, Customer Retention, New Customer Attraction, Small and Medium Enterprises, Jordan

\section{Introduction}

Internet has become an important business and marketing tool with the amazing increase in the internet users around the world. Internet has reached to 50 million users globally in less than 4 years since it started. And there is no other medium in history including T.V. has ever reached that number this fast (It took T.V 13 years to achieve this number).And now the estimated number of internet users around the world is 1.4 billion (www.internetworldstats.com) (2009). And expected to be over two billion users by the year of 2015 (www.eTForecasts.com)(2009).The number of advertisements circulated over the net is reaching 3.5 million daily (www.netmaxmarketing.com)(2009). According to the Census Bureau of the Department of Commerce, the estimate of U.S. retail e-commerce sales on internet for the second quarter of 2009, adjusted for seasonal variation but not for price changes was $\$ 32.4$ billion with an increase of $2.2 \%$ from the first quarter of 2009 (U.S. Department of Commerce - www.census.gov, 2009). Based on the above, almost every company is hitting the internet to reserve a place on the World Wide Web (WWW) with activities ranging from having a web site that would introduce the company with basic information to full transaction process. Therefore marketing scholars developed new concepts to embrace this new media with totally new and modified traditional marketing tools.

\section{Literature Review}

Internet Adoption: The internet can be described as a collection of millions of interconnected computers located in countries throughout the world, that are linked to each other by phone lines and high-speed cables to form one large worldwide network. The internet today is the largest computer network in the world. Over the internet, a gigantic amount of data, text, graphics, sound, voice and live broadcast videos can be transmitted from one computer to another at the speed of light. The internet is quickly becoming the preferred channel of communication by millions of people all over the world, and in business it is a fast, global, and inexpensive way of reaching customers (Gonyea \& Gonyea, 1996). In the early 1990s public interest of the internet exploded as it was opened, including individuals and companies. Full commercial internet connections became available in 1991 with the establishment of the Commercial Internet Association, whose aim was to encourage greater business participation. This led to an expansion of commercial sites, which remain the fastest growing part of the internet today (Hamill \& Gregory, 1997). People in 250 countries use the internet today. Through the internet there are many 
services available, everything from searching for information, electronic newspapers, and e-mail, to discussion groups and ordering of goods and services (Jakobsson, 1998). Many researchers defined internet adoption based on the orientation of their work.

Dholakia and Kshetri (2004) examined the adoption in terms of ownership of a web site and use of the Internet for selling purposes (routinization). Internet adoption was defined as the number of internet applications used by the firm business for business purposes. Three internet applications were considered, namely emailing, banking, and sourcing information from the World Wide Web (Ferrer, et, al., 2003). Another definition by of internet adoption is "Does a company sell or purchase products online on the Internet or through other computer-mediated networks or does it use online technologies other than e-mail to collaborate with business partners in the design of new products, to forecast product demand or to manage capacity or inventory?" This definition aggregates the following e-business functions in the company: online sales, purchases, product design, demand forecasting and resource management. The main e-business applications support one or more of these business functions (Gunasekaran et al., 2002). In another new research, internet adoption is defined as the existence of a transactional website. A simpler definition of a firm internet adoption can be formulated with the existence of a corporate website which provides only basic information about the firm, such as contact telephone numbers, e-mail addresses, or information on the location of the firm branches and does not necessarily imply the capability of allowing online transactions (Fuentes, et al., 2008). Another definition by Karakuy and Khalil (2004) stated that internet adoption is the process through which an organization passes from knowledge of internet application to forming an attitude towered this new capability. In this research, the researcher defines internet adoption as the actual use of internet applications (mainly website, e-mails, and online communications) in marketing activities. This definition was carefully formulated to get over the overlapped use of terms (like internet marketing, e-marketing, internet adopting, internet marketing adoption, online marketing ...etc) found in the literature.

Benefit of Internet Adoption: The only reason why such a new form of marketing spread is the fact that it must bring benefits to the firms, something that goes beyond the traditional one. The following are the major studies and articles discussing the perceived benefits of internet related to the topic of this study. Many other benefits for different aspects of marketing and business can be found. The internet is a unique medium that allows access to information without geographic location constraints. As a communications tool the Internet has the ability of delivering messages enhanced by color, sound, real or animated images as well as two-way interaction. The internet has grown rapidly, doubling in size every year since the mid1990s (Haynes et al., 1998), (Chapman et al., 2000). Internet helps improving the cost, and builds the company faster (Jett, 2002). Internet marketing includes the use of a company website in conjunction with online promotional techniques such as search engines, banner advertising, direct e-mail and links or services from other web sites to acquire new customers and provide services to existing customers that help develop the customer relationship. However, it is necessary to integrate internet marketing with traditional media such as prints and television to be fully effective (Chaffey et al., 2003). With marketing diversifying onto the internet, traditional economies-of-scale advantages in manufacturing, distribution and marketing to maintain low costs and at the same time improving quality are diminishing, as small companies behave and look big (Heinen, 1996).

Internet marketing is a cost effective tool and increase customer loyalty, and consider internet marketing as an effective way to get new customers (Negen, 2007). Internet marketing help predict customer behavior, which make it easier to firms to maintain better relationship with the customers and increase the customer retention by create loyalty (Nematabaksh, 2007). Relationship management (which is directly related to loyalty and customer retention issues) can be build and maintain over the internet marketing (Marketing Week, 2004). Internet and websites as retailer medium can provide better customer relations and control of distribution in a relatively low cost (Okeefa and Conner, 1999). Internet marketing should increase the customer loyalty and accordingly increase customer retention (Alan, 2002).

The internet can be used both as a direct sales channel and as an interactive sales force and marketing tool for communication, which may affect sales performance through achieving direct sales or indirectly through enhancing inter-organizational relationships and implementing sales leads via communication and providing higher levels of productivity by increasing of sustainable customer shares (Avlonitis and Karayanni, 2000). Internet marketing as a tool can be used in almost every traditional marketing concept form the marketing mix to the IMC and relationship marketing (Palumbo and Herbig, 1998). 
Customer - Company Relationship: According to (Mooney, 2002) customer - company relationship is: customers interacting with a company perceive the business as a single entity, despite often interacting with a number of employees in different roles and departments. The relations a combination of policies, processes, and strategies implemented by an organization to unify its customer interactions and provide a means to track customer information. This relation consists of the processes a company uses to track and organize its contacts with its current and prospective customers (Rigby et al., 2002).

Customer Loyalty: Customer loyalty is how likely customers are to return and their willingness to perform partner shipping activities for the organization. Partnership activities include the customers' willingness to spend more while on a property, give positive referrals to others and tell management when problems occur (Kotler et al., 1999). Griffin urges that two factors are critical for loyalty to grow. The first factor is customer's emotional attachment toward one certain product or service. The second factor is customer's repeat purchase (Quoted in Shoemaker and Lewis, 1998). In this research the researcher define customer loyalty as maintaining customer satisfaction which will drive customers to repeat purchasing through enhancing relationship with customers by using internet.

Customer Retention: Customer retention is the maintenance of the patronage of people who have purchased company's goods or services once and the gaining of repeat purchases Customer retention is linked to employee loyalty, since loyal employees build up long-term relationships with customers (CBS Interactive, 2008). In this research the researcher define customer retention as keeping customers from switching to competitors by using internet.

Attracting New Customers: Attracting new customer is "giving peoples a good reason to deal with your firm" (Webtyes, 2009). It is also expanding the firms' client base (Marketing College, 2009).

In this research the researcher define attracting new customers as gaining new customers that never dealt with the company before by using internet.

Hypotheses and Study Model: The current study is based on one main hypothesis and three subhypotheses:

Ha1: customer - company relationship has a positive direct effect on internet adoption.

This hypothesis is broken down into the following hypotheses:

Ha1.1: Customer loyalty has a positive direct effect on internet adoption.

Ha1.2: Customer retention has a positive direct effect on internet adoption.

Ha1.3: Attracting new customers has a positive direct effect on internet adoption.

Figure 1: Study Model

Independent Variable

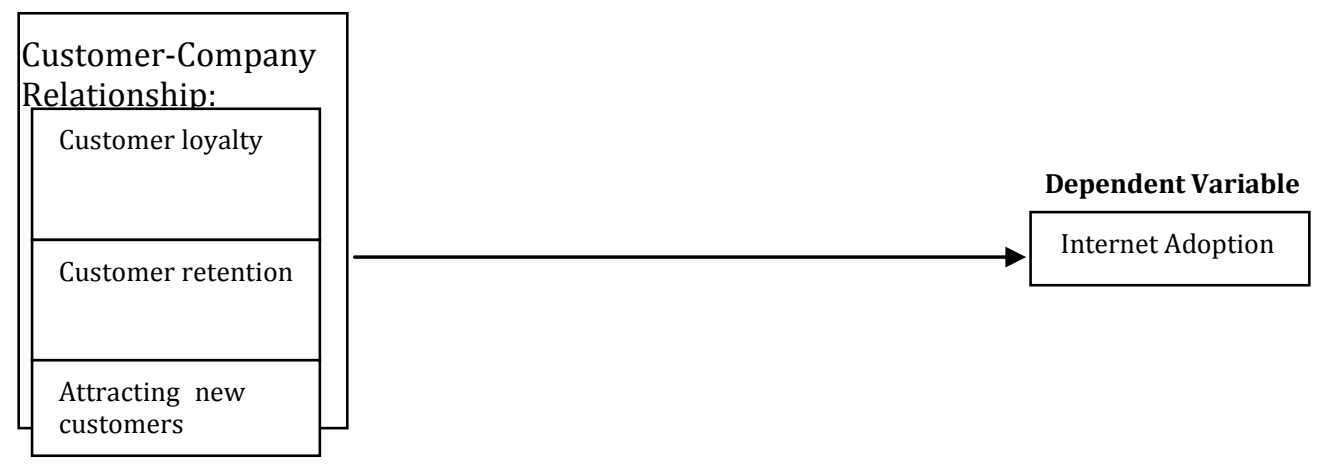

\section{Methodology}

This research is causal research as it aims to identify the effect of the independent variables on the dependent variable directly to test the hypothesis. Quantitative approach was found more consistent with the purpose of this research. Also this research is without any control on the behaviors. As a result of this, 
survey strategy is appropriate and will be used for this research. This research depends on empirical findings and therefore it is of inductive nature.

Study Population and Sample: The population of interest was defined as the top managers of "Jordanian Small and Medium Sized Enterprises" who have both e-mail address and active website. Since the majority of companies are located in the capital Amman, the researcher limited the sampling frame to decision makers of SMEs in the capital. The principal criterion for selection of SMEs was the registered capital because other criteria such as number of employees or revenue are difficult to apply and can cause misleading classifications in the absence of reliable official sources for such information in Jordan as elaborated previously. The targeted population is companies of the second, third, and fourth categories. Which have a registered website and e-mail address (combined together) based on the data obtained from Amman Chamber of Commerce. All the websites mentioned in the official records obtained from Amman Chamber of Commerce for the targeted population were visited to ensure they are active. Inactive company's website eliminates the company from the targeted population list for not matching the criteria the researcher set for the targeted population of this research. Same was done for e-mail, test e-mails were sent to all e-mail addresses mentioned in the official records to ensure they are active. Inactive company's e-mail eliminates the company from the targeted population list as well. The percentage of each category to the total targeted population based on the official records was as follow:

- $\quad$ Second category $6 \%$ of the population.

- Third category $71.4 \%$ of the population.

- $\quad$ Forth category $22.6 \%$ of the population.

The sampling design used is restricted probability sampling; proportionate stratified random sampling process was used. To ensure the survey sample represents the targeted population, a systematic sampling method was adopted using a list of the members of the targeted population. This procedure accomplished the same end as simple random sampling with more efficiency. According to Burns and Bush (1998) this sampling method guarantees every member of the population has a known and equal chance of being selected into the sample. Therefore, the resulting sample, no matter what size, will be a valid representation of the population. After systematic sampling method the number of enterprises is 270 for the three categories.

Data Collection Method: Sekaran (2003) stated that the main three data collection methods used in survey researched are: interviewing, administering questionnaires, and observing people and phenomena, depending on the nature of the research and the facilities available. Personally administrated questionnaires were used to collect the research data. The questionnaire consists of four parts: part one gathers demographic information about the decision maker. Part two gathers information about the firms. Part three gather information about the nature of adoption and actual use of internet (dependent variables).Part four gathers information about the effect customer - company relationship on the adoption and actual use on internet (independent variable). Part three and part four are of five points Likert scale format.

Sample Description: Upon the receiving of the questioners and after the filtering and screening process is completed, 253 questionnaires remained. Table (1) shows the description of the sample by presenting the Frequency and Percentages of the Demographic Variables and Firms Characteristics.

Table 1: Sample Description

\begin{tabular}{llll}
\hline Variables & Category & Frequency & Percent \\
\hline \multirow{4}{*}{ Age } & $18<29$ & 17 & 6.7 \\
& $29<39$ & 44 & 17.4 \\
& $39<49$ & 173 & 68.4 \\
& $49<$ yeas and more & 19 & 7.5 \\
Educational Level & Total & 253 & $100.0 \%$ \\
& 2 years diploma and below & 22 & 8.7 \\
Gender & Bachelor degree & 202 & 79.8 \\
& Post graduate & 29 & 11.5 \\
& Total & 253 & $100.0 \%$
\end{tabular}




\begin{tabular}{|c|c|c|c|}
\hline & Females & 34 & 13.4 \\
\hline & Total & 253 & $100.0 \%$ \\
\hline \multirow{6}{*}{ Experience } & Less than 6 years & 19 & 7.5 \\
\hline & $6<13$ years & 27 & 10.7 \\
\hline & $13<20$ years & 60 & 23.7 \\
\hline & $20<27$ years & 139 & 54.9 \\
\hline & 27 years and more & 8 & 3.2 \\
\hline & Total & 253 & $100.0 \%$ \\
\hline \multirow{4}{*}{ Firm's Size } & Second category & 15 & 5.9 \\
\hline & Third category & 183 & 72.3 \\
\hline & Fourth category & 55 & 21.7 \\
\hline & Total & 253 & $100.0 \%$ \\
\hline \multirow{6}{*}{$\begin{array}{l}\text { Presence } \\
\text { Market }\end{array}$} & Less than 5 years & 20 & 7.9 \\
\hline & $5<11$ years & 45 & 17.8 \\
\hline & $11<17$ years & 23 & 9.1 \\
\hline & $17<23$ years & 129 & 51.0 \\
\hline & 23 years and more & 36 & 14.2 \\
\hline & Total & 253 & $100.0 \%$ \\
\hline \multirow{5}{*}{$\begin{array}{l}\text { Internet } \\
\text { Period }\end{array}$} & Less than 3 years & 9 & 3.6 \\
\hline & $3<6$ years & 25 & 9.9 \\
\hline & $6<9$ years & 62 & 24.5 \\
\hline & 9 years and more & 157 & 62 \\
\hline & Total & 253 & $100.0 \%$ \\
\hline
\end{tabular}

Reliability: The reliability of a measure indicates the extent which it is without bias (error free) and hence ensures consistent measurement across time and across various items in instrument (Sekaran, 2003).Operationally, reliability is defined as the internal consistency of a scale, which assesses the degree to which the items are homogeneous. The reliability of the research constructs were assessed by examining the Cronbach Alpha Coefficient. (Sekaran, 2003).The criterion that is used in the research to examine the reliability of each variable is that if Cronbach's Alpha value is over 0.70 , it is considered as a sound and reliable measure (Nunnaly, 1978). Table (2) shows the reliability coefficients for the research constructs. It shows that the reliability coefficients' of all the research variables were above the Cronbach's Alpha cut-off point (0.70) used in this research, indicating that the research domains are reliable (checked by internal consistency reliability: Cronbach Alpha).

Table2: Chronbach's Alfa Reliability Coefficient

\begin{tabular}{llllll}
\hline Domain & Sub - Domain & $\begin{array}{l}\text { Number } \\
\text { Items }\end{array}$ & $\begin{array}{l}\text { of } \\
\text { Value }\end{array}$ & Alpha \\
& Customer Loyalty & 5 & 0.892 & \\
Customer - Company & Customer Retention & 4 & 0.849 & \\
Relationship (independent) & Attracting New & 4 & 0.817 & \\
& Customer & 13 & 0.935 & \\
Internet Adoption (dependent) & Total & 13 & 0.958 & \\
\hline
\end{tabular}

The table indicates the results of cronbach alpha test (internal consistency reliability) for each domain. The values of cronbach alpha suggest a high internal consistency in each domain reflecting a valid reliability. All values exceed 0.70 (which expresses the lowest valid value for the internal consistency reliability).

\section{Results}

\section{Testing the Study Hypotheses}

Ha1: customer - company relationship has a positive direct effect on internet adoption.

This hypothesis is broken down into the following hypotheses: 
Ha1.1: Customer loyalty has a positive direct effect on internet adoption.

Ha1.2: Customer retention has a positive direct effect on internet adoption.

Ha1.3: Attracting new customers has a positive direct effect on internet adoption.

The main hypothesis is tested throughout the components of customer - company relationship (loyalty, customer retention, and attracting new customers) using simple linear regression analysis to investigate the special relationship (table 3), and using multiple regression analysis to investigate the effect strength of the components on the adoption simultaneously (table 4).

Table 3: Regression Analysis

\begin{tabular}{lllllllll}
\hline Component & $\mathbf{R}^{2}$ & $\mathbf{f}$ & Sig(f) & $\mathbf{t}$ & $\mathbf{S i g}(\mathbf{t})$ & $\begin{array}{l}\boldsymbol{\alpha} \\
\text { Constant }\end{array}$ & $\boldsymbol{\beta}$ Coefficient & $\begin{array}{l}\text { Alternative } \\
\text { Hypothesis } \\
\text { decision }\end{array}$ \\
\hline Loyalty & 0.390 & 160.71 & 0.000 & 12.67 & 0.000 & 1.253 & 0.683 & Accept \\
$\begin{array}{l}\text { Retention } \\
\begin{array}{l}\text { Attracting New } \\
\text { Customers }\end{array}\end{array}$ & 0.274 & 94.51 & 0.000 & 9.72 & 0.000 & 1.891 & 0.515 & Accept \\
$\begin{array}{l}\text { Customer - } \\
\begin{array}{l}\text { Company } \\
\text { Relationship }\end{array}\end{array}$ & 0.207 & 65.54 & 0.000 & 8.09 & 0.000 & 2.052 & 0.474 & Accept \\
\hline
\end{tabular}

Critical $f$ at 0.05 level $=3.89$ (degree of freedom $1 \& 251$ )

The table indicates the results of simple linear regression analysis for the customer - company relationship on the internet adoption. All $\mathrm{f}$ values were greater than the critical value indicating significant relationship between the customer - company relationship components and internet adoption. The values of R2 shows the relative importance of each component on the dependent variable (internet adoption), loyalty was the most important component as R2 was found to be 0.39 followed by customer retention 0.274 and attracting new customers 0.207 . When investigating the customer - company relationship as whole factor, $\mathrm{R} 2$ was found to be 0.322 . This value suggests a weak contribution to the internet adoption (less than 0.400).The $t$ statistic shows that a linear relationship exists between each component and internet adoption, this is as all $t$ values were significant (sig values were less than 0.05) indicating that each component is important to internet adoption while this importance is clearly quantified by R2 values given. Upon the results of the table, the alternative hypothesis is accepted and the null is rejected.

Table 4: Multiple Linear Regression Analysis Using Stepwise Method

\begin{tabular}{lllllllll}
\hline Component & $\mathbf{R}^{2}$ & $\mathbf{f}$ & $\operatorname{Sig}(\mathbf{f})$ & $\mathbf{t}$ & $\operatorname{Sig}(\mathbf{t})$ & $\begin{array}{l}\boldsymbol{\alpha} \\
\text { Constant }\end{array}$ & $\begin{array}{l}\boldsymbol{\beta} \\
\text { Coefficient }\end{array}$ & $\begin{array}{l}\text { Alternative } \\
\text { Hypothesis } \\
\text { decision }\end{array}$ \\
\hline Loyalty & 0.390 & 160.71 & 0.000 & 12.67 & 0.000 & 1.253 & 0.683 & Accept \\
\hline
\end{tabular}

Critical $f$ at 0.05 level $=3.89$ (degree of freedom 1\&251)

The table indicates the results of multiple linear regression analysis for the customer -company relationship on the internet adoption to investigate the effect of all customers -company relationship components simultaneously. The $f$ value was greater than the critical $f$ value indicating significant relationship between the customer - company relationship components and internet adoption. The value of R2 shows that loyalty was the most important component as it was the unique contributor of 0.39 .This value suggests a weak contribution to the internet adoption (less than 0.400 ). The t-statistic shows that a linear relationship exists between loyalty and internet adoption, this is as all $t$ values were significant (sig values were less than 0.05 ) expressing the important of loyalty to internet adoption.

Upon the results of the table, the alternative hypothesis is accepted and the null is rejected. 


\section{Conclusion}

Based on the above findings of the study the researcher made the following conclusions: Customer company relationship has a positive direct effect on Internet adoption in Jordanian Small and Medium Enterprises. However, customer - company relationship has a weak effect on internet adoption in Jordanian Small and Medium Enterprises, since R2 values were lower than 0.400 as presented in table (3).As for the components of the Customer - company relationship, loyalty was found to be the most important effect to internet adoption, where R2 was very close to 0.400 as presented in table (4). The rest of the components (customer retention, and attracting new customers) have weak contribution to the internet adoption. This indicate that the Jordanian SMEs are not adopting internet based on the expected benefits for business and marketing, such a result show that Jordanian SMEs are either not aware or not ready to utilize internet adoption for activities related to customer - company relationship.

Limitation of the Research: There are number of limitations related to this research: the geographical limitation, as this research focused on the SMEs in Amman the capital. It is true that the capital has most of the business share in Jordan but other cities were excluded. Lack of resources is another limitation to cover bigger sample. the sample was drafted from the official recodes of Amman Chamber of Commerce, those records are supposed to be updated but unfortunately few companies update their information voluntarily at the Chamber before the need of renewing their registration which is done normally at the beginning of every new year, which means that if any changes occurred during the first months of the year its most likely will not to be reported to the Chamber. This might have some effect on the targeted population and on the sample selection accordingly.

Recommendations: Based on the findings and results of the research, the researcher strongly recommends taking some actual measures to explain the potential of internet as a marketing tool for SMEs. Official programs by the government should be conducted. Part of the international programs aid in Jordan should consider such measures. Customer - company relationship and other marketing activities should be considered by Jordanian SMEs. Based on the literature review and studies conducted in developed and well developed countries, the use of internet in enhancing and maintaining customer company relationship can benefit the SMEs tremendously which will be reflected on the performance and the help expanding the SMEs. Should that happened; it will positively affect the economy and the unemployment problem in Jordan.

Future Research: Future researches may examine other marketing activities and their effect on internet adoption. Another area of future research is to investigate the effect of moderating variables on this relationship. Also, applying the same research on other companies' size categories (like the large companies and micro companies) is an important future research area to compare the results with this research. A future research on the barriers of internet adoption in marketing activities could help better understanding the result of this research. Researches that can overcome the limitation of this research are also a good area of future research.

\section{References}

Alan, D. S. (2002). Loyalty and e-Marketing Issues. Quarterly Journal of Electronic Commerce, 3(2), 149161.

Avlonitis, G. J. \& Karayanni, D. A. (2000).The Impact of Internet Use on Business-to-Business Marketing: Examples from American and European Companies. Industrial Marketing Management, 29(5), 44159.

Burns, A. C. \& Bush, R. F. (1998). Marketing Research. Third edition. Prentice Hall International, Inc.: New Jersey.

Chaffey, D., Mayer, R., Johnston, K. \& Ellis-Chadwich, F. (2003). Internet Marketing, Strategy, Implementation and Practice. Harlow, UK: Prentice Hall. London.

Chapman, P., James-Moore, S. M. \& Thompson, D. (2000). Building Internet Capabilities in SMEs. Logistics Information Management, 13, 353- 360.

Dholakia, R. R. \& Kshetri, N. (2004).Factors impacting the Adoption of the Internet among SMEs. Small Business Economics, 23(4), 311-322.

Ferrer, S. R. D., Schroder, D. H. \& Ortmann, G. F. (2003). Internet Use and Factors Affecting the Adoption of internet Applications. Sugarcane Farm Business in the Kwazulunatal Midlands. Contributed Paper 
Presented at the 41st Annual Conference of the Agricultural Economic Association of South Africa (AEASA), October 2-3, Pretoria, South Africa.

Fuentes, R., Murillo, R. \& Llobet, G. (2008).Strategic Online -Banking Adoption. CEMFI. Working Paper No. 0813, September. Casadodel Alisal.

Gonyea, J. C. \& Gonyea, W. M. (1996). Selling on the Internet: How to Open an Electronic Store Front and Have Millions of Customers Come to You. New York. McGraw-Hill.

Gunasekaran, A., Marri, H. B., McGaughey, R. E. \& Nebhwani, M. D. (2002). E-Commerce and its Impact on Operations Management. International Journal of Production Economics, 75(2), 185- 197.

Hamill, J. \&Gregory, K. (1997). Internet Marketing in the Internationalization of UK SMEs. Journal of Marketing Management, 13(1), 9-28.

Haynes, P., Becherer, R. \& Helms, M. (1998). Small and medium sized Business and Internet use: Internet Research. Electronic Networking Application and Policy, 8(3).

Heinen, J. (1996). Internet Marketing Practice. Information Management \& Computer Security, 4(5), 7-14.

Jakobsson, P. (1998). Internet as Strategic Communication. Lund: Student Literature.

Jett, K. R. (2002). E-Marketing Proof of Savings. Credit Union Management, 29, 13.

Karakuy, F. \& Khalil, O. (2004).Determinants of Internet Adoption in Small and Medium-Sized Enterprises. International Journal of Internet and Enterprise Management, 2(4), 341-364.

Kotler, P., Bowen, J. \& Makens, J. (1999). Marketing for Hospitality and Tourism. International edition. Prentice Hall. New Jersey.

Mooney, P. K. (2002). The Ten Demandments. USA: Blacklick, OH. McGraw-HillCompanies.

Negen, B. (2007). Excelling at e-Marketing. American Nurseryman, 1, 28-30.

Nematabaksh, M. A. \& Solgi, M. (2007).Personalization Model for e-Marketing. IMECS, 1, 845-849.

Nunnaly, J. (1978).Psychometric theory. New York: McGraw-Hill.

O'Keefe, M. \& Conner, G. (1999). Early Adopter of the Web as a Retail Medium. European Journal of Marketing, 32(7/8), 629-643.

Palumbo, F. \& Herbig, P. (1998).International Marketing Tool: The Internet. Industrial Management \& Data Systems, 98(6), 253-61.

Rigby, K., Frederick, F. \& Schefter, P. (2002). Avoid the Four Perils of CRM. Harvard Business Review, 80 (2), 101-109.

Sekaran, U. (2003). Research Methods for Business, A Skill Building Approach, Fourth Edition, John Wiley \& Sons Inc, New York.

Shoemaker, S. \& Lewis, R. C. (1998).Customer loyalty: The future of hospitality marketing. Hospitality Management Journal, 18, 345-370.

\section{Websites}

www.ammanchamber.org Amman Chamber of Commerce

www.cbs.com

www.census.gov US Department of Commerce.

www.etforecasts.com

www.internetworldstats.com

www.marketingcollege.net/short-attracting-new-customers.html

www.marketingweek.co.uk/archive

www.netmaxmarketing.com 